\title{
Arterial Distensibility as a Possible Compensatory Mechanism in Chronic Aortic Regurgitation
}

\author{
Liliane Kope, Fávio Tarasoutchi, Caio Medeiros, Ricardo T. Canvalho, Max Ginberg Silvia G Lage
}

São Paulo, SP - Brazil

\begin{abstract}
Objective - To evaluate elastic properties of conduit arteries in asymptomatic patients who have severe chronic aortic regurgitation.
\end{abstract}

Methods - Twelve healthy volunteers aged $30 \pm 1$ years (control group) and 14 asymptomatic patients with severe aortic regurgitation aged $29 \pm 2$ years and left ventricular ejection fraction of $0.61 \pm 0.02$ (radioisotope ventriculography) were studied. High-resolution ultrasonography was performed to measure the systolic and diastolic diameters of the common carotid artery. Simultaneous measurement of blood pressure enabled the calculation of arterial compliance and distensibility.

Results - No differences were observed between patients with aortic regurgitation and the control group concerning age, sex, body surface, and mean blood pressure. Pulse pressure was significantly higher in the aortic regurgitation group compared with that in the control group $(78 \pm 3$ versus $48 \pm 1 \mathrm{mmHg}, P<0.01)$. Arterial compliance and distensibility were significantly greater in the aortic regurgitation group compared with that in the control group $\left(11.0 \pm 0.8\right.$ versus $8.1 \pm 0.710^{-10} \mathrm{~N}^{-1} \mathrm{~m}^{4}, P=0.01 \mathrm{e}$ and $39.3 \pm 2.6$ versus $31.1 \pm 2.010^{-6} \mathrm{~N}^{-1} \mathrm{~m}^{2}, P=0.02$, respectively).

Conclusion - Patients with chronic aortic regurgitation have increased arterial distensibility. Greater vascular compliance, to lessen the impact of systolic volume ejected into conduit arteries, represents a compensatory mechanism in left ventricular and arterial system coupling.

Key words: chronic aortic regurgitation, arterial distensibility, elasticity

Heart Institute, Clínicas Hospital, University of São Paulo- FMUSP Mailing address: Liliane Kopel - InCor - Unidade Clínica de Terapia Intensiva Geral - Av. Dr. Enéas C. Aguiar, 44 - 05403-000 - São Paulo, SP - Brazil - E-mail: dcllili@incor.usp.br
The elastic properties of great arteries determine the pulsatile component of afterload and influence the performance of the left ventricle ${ }^{1-4}$, especially when ventricular dysfunction is present ${ }^{5,6}$.

The importance of the great arteries in absorbing the impact of the oscillations caused by the alternating function of the heart must be particularly highlighted in patients with aortic regurgitation, in which a very large stroke volume is ejected into the proximal aorta at each systole.

Dilation occurs during the development of chronic aortic regurgitation, and, later, left ventricular dysfunction occurs associated with symptoms and the worsening of the prognosis ${ }^{7}$. Several factors are involved in the maintenance of left ventricular function in chronic aortic regurgitation, and the role of afterload is little known in this process.

The objective of the present study is to evaluate the elastic properties of great arteries in asymptomatic patients with severe chronic aortic regurgitation and preserved left ventricular function.

\section{Methods}

Fourteen patients with severe isolated aortic regurgitation were studied, the mean age was $29 \pm 2$ years, and 11 were men and 3 were women. Patients did not have clinical symptoms of congestive cardiac regurgitation (functional class I, NYHA). The cause of valvular dysfunction was rheumatic fever in all cases. The mean ejection fraction of the left ventricle, assessed through radioisotope ventriculography, was $0.61 \pm 0.02$. Echodopplercardiography was performed in patients prior to the study. All patients had sinus rhythm on echocardiography at the time the examination was performed, and they were not taking medication before or after its performance.

The control group included 12 healthy volunteers who had no history of previous cardiovascular or systemic disease. The mean age was $30 \pm 1$ years, 11 were men, and one was a woman.

Informed consent was obtained from all participants prior to the beginning of the study, according to the Ethics 
Committee of the Hospital das Clínicas of the School of Medicine of the University of São Paulo.

Patients and healthy volunteers lying in the supine position were studied after they had rested in a quiet and dimmed environment for 15 minutes. Ultrasound equipment (Ultramark-8, Advanced Technology Laboratories Inc., Bothell, USA), with a high-resolution transducer (7.5MHz), was used to obtain two-dimensional images of the common carotid artery, in a longitudinal section of its cephalic portion $1 \mathrm{~cm}$ below the bifurcation. The transducer was positioned at $90^{\circ}$ to the vessels, so that adventitial, medial and intimal layers were clearly discernible. The inner echogenic line is generated by the intimal surface ${ }^{8}$. Parallel to this line we observed a hypoechoic space, the medial surface, and another echogenic line: the images of the adventitia carotid arteries were obtained by the same observer and were coupled with the simultaneous echocardiogram and videotaped for later measurement of arterial diameter.

Systemic blood pressure was obtained by upper arm sphygmomanometry, simultaneously with the acquisition of an ultrasound image of the carotid artery obtained with an automated oscillometric method (Dinamap, Critikon Inc., Tampa, Florida). Mean blood pressure was calculated by adding diastolic pressure and a third of the pulse pressure.

Based on electrocardiography records, images were selected at time points that corresponded to systolic expansion of the carotid artery (within 60ms of the electrocardiography $\mathrm{T}$ wave), and with diastolic relaxation (concurrent with the onset of the electrocardiography $\mathrm{R}$ wave). These images were recorded in a computer equipped with video-frame grabber (Willow Publishers VGA, Willow Peripherals, Inc., Bronx, NY, USA) for later determination of carotid artery diameter, using a computer program developed for this purpose. The posterior wall boundary (far wall) corresponding to the interface between the lumen and intima and anterior wall boundary (near wall) corresponding to the interface of the adventitia and media (fig. 1) were traced. Once the boundaries were traced, an automated algorithm was used to determine artery diameter. An average of 3 to 5 measures in different images was used to determine the final diameter of the artery in systole and diastole. The interobserver variability pertaining to measurements of carotid artery diameter was $1.5 \pm 1.0 \%$ and the intraobserver variability was $1.0 \pm 0.8 \%$.

Artery distensibility and compliance measures of the artery elastic properties that relate artery diameter variability to a corresponding variability of simultaneous blood pressure were determined, according to the following equation ${ }^{10}$ :

$$
\begin{aligned}
& \text { Distensibility }=\frac{2(\mathrm{Ds}-\mathrm{Dd}) / \mathrm{Dd}}{\mathrm{SBP}-\mathrm{DBP}}\left(\mathrm{N}^{-1} \cdot \mathrm{M}^{2}\right) \\
& \text { Arterial Compliance }=\frac{(\mathrm{Ds}-\mathrm{Dd})}{2(\mathrm{SBP}-\mathrm{DBP})} \pi \mathrm{Dd}\left(\mathrm{N}^{-1} \cdot \mathrm{M}^{4}\right)
\end{aligned}
$$

Where: Ds-the carotid artery diameter in systole $(\mathrm{mm})$; Dd-carotid artery diameter in diastole (mm); SBP-systolic blood pressure (mmHg); DBP-diastolic blood pressure ( $\mathrm{mm} \mathrm{Hg}$ ).

Data are presented as mean \pm standard error. Comparison of averages between the groups (control and aortic re-

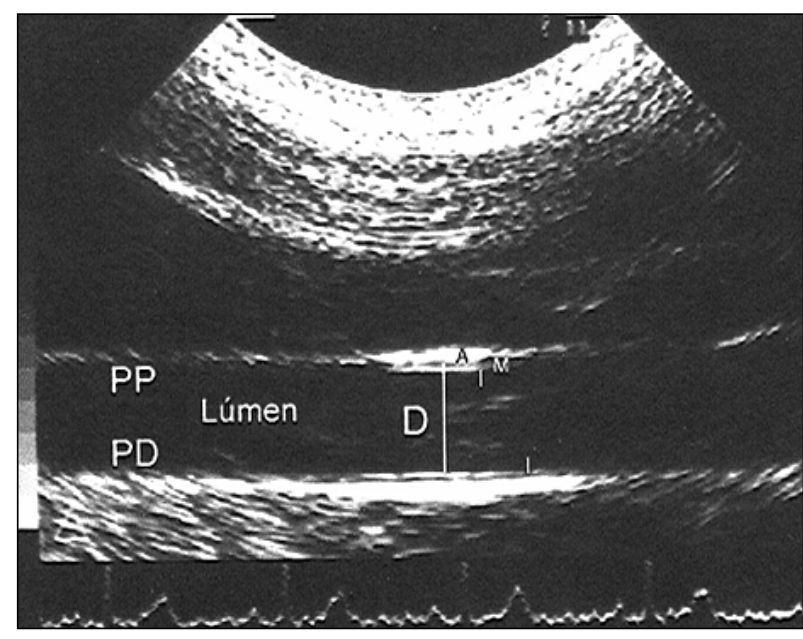

Fig. 1 - Two-dimensional image of common carotid artery longitudinal cut. PW proximal wall; DW - distal wall; A- adventitious layer; M - middle layer; I- inner layer; D - arterial diameter.

gurgitation) was performed using the $t$ test for independent samples. Analysis of equality proportions between the two groups was made using Fisher's exact test. Statistical significance was accepted as $5 \%(\mathrm{p}<0.05)$.

\section{Results}

Echocardiographic assessment showed that patients with aortic regurgitation had left ventricle diastolic diameters of $71 \pm 2 \mathrm{~mm}$, and left ventricle systolic diameters of $34 \pm 1 \%$. Record through Doppler method defined aortic regurgitation as significant in all patients.

Patients in the aortic regurgitation group were no different from the control group regarding age ( $29 \pm 2$ vs. $30 \pm 1$ years, $\mathrm{P}=0.67)$, sex ( 11 men and 3 women vs. 11 men and 1 woman, $\mathrm{P}=0.60$ ), weight $(72 \pm 4$ vs. $74 \pm 2 \mathrm{Kg}, \mathrm{P}=0.61)$, height $(168 \pm 3$ vs. $175 \pm 2 \mathrm{~cm}, \mathrm{P}=0.06)$ and body surface $(1.82 \pm 0.06 \mathrm{vs}$. $\left.1.90 \pm 0.02 \mathrm{~m}^{2}, \mathrm{P}=0.23\right)$.

Mean blood pressure was the same in both groups; however, systolic pressure was significantly higher and diastolic was significantly lower in patients with aortic regurgitation. Pulse pressure was significantly higher in patients with aortic regurgitation (tab. I).

Assessment of carotid artery diameter showed that no difference existed in diastolic diameter between the two groups. However, at the time of systolic expansion, carotid artery diameter was significantly greater in patients in the aortic regurgitation group. The difference between systolic and diastolic diameter was significantly greater in the aortic regurgitation group compared with that in the control group (tab.I).

Artery compliance and distensibility were significantly greater in patients with chronic aortic regurgitation compared with that in the volunteers of the control group (tab. I).

\section{Discussion}

Maintaining the systolic function of the left ventricle enables patients with severe aortic regurgitation to remain 


\begin{tabular}{|c|c|c|c|}
\hline \multicolumn{4}{|c|}{$\begin{array}{l}\text { Table I - Hemodynamic characteristics and elastic properties } \\
\text { the arteries in the control group and in the aortic regurgitation } \\
\text { group (ARo) }\end{array}$} \\
\hline & $\begin{array}{c}\text { Control group } \\
(\mathrm{n}=12)\end{array}$ & $\begin{array}{c}\text { Aro group } \\
(\mathrm{n}=14)\end{array}$ & $\mathrm{P}$ \\
\hline \multicolumn{4}{|c|}{ Blood pressure (mmHg) } \\
\hline Systolic & $116 \pm 2$ & $132 \pm 4$ & $<0.01$ \\
\hline Diastolic & $68 \pm 2$ & $54 \pm 2$ & $<0.01$ \\
\hline Mean & $84 \pm 2$ & $80 \pm 2$ & 0.24 \\
\hline Pulse pressure & $48 \pm 1$ & $78 \pm 3$ & $<0.01$ \\
\hline \multicolumn{4}{|c|}{ Carotid artery diameter (mm) } \\
\hline Systolic (Ds) & $6.28 \pm 0.17$ & $7.20 \pm 0.19$ & $<0.01$ \\
\hline Diastolic (Dd) & $5.71 \pm 0.15$ & $5.98 \pm 0.16$ & 0.23 \\
\hline Ds-Dd & $0.57 \pm 0.05$ & $1.22 \pm 0.10$ & $<0.01$ \\
\hline $\begin{array}{l}\text { Arterial } \\
\text { compliance (10 }\end{array}$ & $8.1 \pm 0.7$ & $11.0 \pm 0.8$ & 0.01 \\
\hline $\begin{array}{l}\text { Arterial } \\
\text { distensibility }\end{array}$ & $\left.\mathrm{n}^{2}\right) \quad 31.1 \pm 2.0$ & $39.3 \pm 2.6$ & 0.02 \\
\hline
\end{tabular}

asymptomatic or with few symptoms during a long time period. Identifying the factors involved in the worsening of the symptoms and of prognosis is important so that the natural course of the disease can be altered ${ }^{11}$.

Our findings show that elastic properties of the great arteries, expressed by artery distensibility and compliance, must play an important role in left ventricular-arterial system coupling in patients with aortic regurgitation. In our population of asymptomatic patients with preserved ventricular function, we found an increase in the capacity of the great arteries to absorb the oscillations caused by the great systolic volume ejected each systole, due to the greater carotid artery compliance and distensibility compared with that in the healthy volunteer group.

The participation of the elastic properties of the great arteries, as a factor that contributes to the maintenance of left ventricular function in aortic regurgitation, is the object of interesting.

The study of elastic artery properties, in an experimen- tal model of aortic regurgitation, reports that increased distensibility in the aorta results in a decrease in its characteristic impedance after development of valvar regurgitation ${ }^{12}$. Thus, greater distensibility of the artery is considered an adaptation mechanism to the acute increase of total systolic volume.

The adaptation of the arterial system in patients with chronic aortic regurgitation was analyzed by Devlin et al. ${ }^{13}$, who observed a decrease in arterial elastance in patients with impaired left ventricular contractility and preserved ejection fraction. However, those with impaired contractility and reduced left ventricular ejection fraction had an increase in arterial elastance, with consequent increase in left ventricular afterload and deterioration in ef left ventricular performance, thus concluding that maladaptation of the arterial system is a mechanism that contributes to progressive dysfunction of the left ventricle in chronic aortic regurgitation. We should emphasize that, unlike the noninvasive approach that we used, analysis of total arterial elastance is an invasive approach that does not enable separation of the elastic properties of the great arteries and arterioles.

Studying age as a factor involved in progressive dilation and left ventricular dysfunction, Wilson et al. ${ }^{14}$ suggests that the decrease in aortic distensibility, associated with increasing age, contributes to maladaptation of left ventricular function observed during evolution of chronic aortic regurgitation.

Our study shows that young asymptomatic patients, with aortic regurgitation, have a vascular reserve, that is, they possess greater arterial distensibility when compared with the healthy group, which diminishes the impact of the increased systolic volume.

We need further investigation into the influence of duration of the disease, development of symptoms, and left ventricular dysfunction over the elastic properties of the arteries in chronic aortic regurgitation. It is possible that this analysis presents more data that will help in choosing a treatment for this disease.

\section{References}

1. Urschel CW, Covell JW, Sonnenblick EH, Ross J, Braunwald E. Effects of decreased aortic compliance on performance of the left ventricle. Am J Physiol 1968; 214: 298-304

2. Elzinga $G$, Westerhof N. Pressure and flow generated by the left ventricle against different impedance. Circ Res 1973; 32: 178-86.

3. Weber KT, Janicki JS, Hunter WC, Shroff S, Pearlman ES, Fishman AP. The contractile behavior of the heart and its functional coupling to the circulation. Prog Cardiovasc Dis 1982; 24: 375-400.

4. Sunagawa K, Maugham WL, Sagawa K. Stroke volume effect of changing arterial input impedance over selected frequency ranges. Am J Physiol 1985; 248: H477-84.
5. Maruyama Y, Nishioka O, Nozaki E, et al. Effects of arterial distensibility on left ventricular ejection in the depressed contractile state. Cardiovasc Res 1993; 27 : $182-7$

6. Lage SG, Kopel L, Monachini MC, et al. Carotid arterial compliance in patients with congestive heart failure secondary to idiopathic dilated cardiomyopathy. Am J Cardiol 1994; 74: 691-5.

7. Tarasoutchi F, Grinberg M, Parga Filho J, et al. Relação entre função ventricular esquerda e desencadeamento de sintomas na insuficiência aórtica crônica severa. Arq Bras Cardiol 1995; 64: 301-9. 
8. Pignoli P, Tremoli E, Poli A, Oreste P, Paoletti R. Intimal plus medial thickness of the arterial wall: a direct measurement with ultrasound imaging. Circulation 1986; 74: 1399-406.

9. Kopel L, Lage SG. Avaliação das propriedades elásticas arteriais utilizando a ultra-sonografia de alta resolução vascular em indivíduos normais. Radiol Bras 1995; 28: 131-5.

10. Van Merode T, Hick PJJ, Hoeks APG, Rahn KH, Reneman RS. Carotid artery wall properties in normotensive and borderline hypertensive subjects of various ages. Ultrasound Med Biol 1988; 14: 563-9.

11. Tarasoutchi F, Grinberg M, Parga Filho J, et al. Symptoms, left ventricular function, and the timing of valve replacement surgery in patients with aortic regurgitation. Am Heart J 1999; 138: 477-85.

12. Wainai Y. Adaptive mechanisms of the aorta and left ventricle to volume overloading following abrupt aortic regurgitation in rabbits. Cardiovasc Res 1991; 25: 463-7.

13. Devlin WH, Petrusha J, Briesmiester K, Montgomery D, Starling MR. Impact of vascular adaptation to chronic aortic regurgitation on left ventricular performance. Circulation 1999; 99: 1027-33.

14. Wilson RA, McDonald RW, Bristow JD, et al. Correlates of aortic distensibility in chronic regurgitation and relation to progression to surgery. J Am Coll Cardiol 1992; 19: 733-8. 